\title{
Expansion volume of alkali activated foamed cork composites from tungsten mining mud waste with aluminium
}

\author{
Imed Beghoura ${ }^{1 *}$, Joao Castro-Gomes ${ }^{1}$, Haroon Ihsan ${ }^{2}$, John Pickstone ${ }^{2}$, Nuno Estrada ${ }^{3}$ \\ ${ }^{1}$ Centre of Materials and Building Technologies (C-MADE), Department of Civil Engineering and Architecture, University of Beira \\ Interior (UBI), 6201-001 Covilhã, Portugal. \\ ${ }^{2}$ Alsitek Limited, Peterborough, UK. \\ ${ }^{3}$ Sofalca Sociedade Central de Produtos de Cortiça, Lda, Abrantes, Portugal.
}

\begin{abstract}
Several mixes of alkali activated foams from tungsten mud waste (MW), grounded glass (GG) and metakaolin (MK) were developed incorporating expanded granulated cork (EGC). This study presents preliminary results of the expansion process obtained with the addition of aluminium (AL) powder as a foaming agent. $0.3 \mathrm{wt} . \%, 0.4 \mathrm{wt} . \%$ to $0.5 \mathrm{wt} . \%$ of $\mathrm{AL}$ powder were added to the alkali activated matrix. The physical and mechanical properties of the obtained foams, the effects of the type and amount of the foaming agent added are presented and discussed. Highly porous structures were obtained, with overall expansion up to $68.2 \%$ when the AL powder was added. The size and distribution of pores are shown. The compressive strength of foams in the case of highly porous structures achieved of $1.2 \mathrm{MPa}$ for the samples containing 0.5 wt. $\%$ of AL powder. Mechanical and thermal properties of the cured structure are good and can therefore be used for applications in acoustic panels and lightweight prefabricated components for thermal insulation purposes.
\end{abstract}

\section{Introduction}

A lot of research is currently being carried out to produce alkali activated material from mining waste [1], and the focus is to reuse the waste materials by integrating them into the manufacture of new materials [2], the EU and other countries have committed to the reutilization of the mineral wastes as precursor materials for alkali activated binders from an environmental, technical and economic point of view [3] [1].

The Panasqueira tungsten mining waste in Covilhã, Castelo Branco District, Portugal (figure 1) present a very good reactivity with alkaline activators such as calcium hydroxide, for high alkali concentration and the mechanical strength thru curing at room temperature was improved later on by mixing the mud waste (MW) with different source of silica (river sand and amorphous ground waste glass) and cured at moderate temperatures [4] [5].

Recently, alkali activated foamed materials have been proposed as a novel idea which involves the production of the lightweight materials combining the performance and the benefits of energy saving (carbon footprint) with the cradle-to-gate emission reductions obtained [6] [7].

In the last few years, several examples of alkali activated foams have been obtained from different raw materials [8] [9]. One of the used methods to produce alkali activated materials is the thermal expansion of (Na, K)-poly (silicate-multisiloxo) [10].
Various chemical foaming agents can be used in the foaming process of inorganic polymers. For example, AL powder has been used to produce foams of inorganic polymers [11] [12] as a chemical foaming agent. The reaction between the $\mathrm{AL}$ powder and the alkaline activator takes place very quickly, as shown in equation (1); [13].

$$
2 \mathrm{Al}+2 \mathrm{NaOH}+2 \mathrm{H}_{2} \mathrm{O} \rightarrow 2 \mathrm{NaAlO}_{2}+3 \mathrm{H}_{2} .
$$

Currently, cork has found a wide range of application in the building industry as a solution for lightweight, thermal insulation and shows good environmental advantages [14]. Karad [15] studied the influence of cork granules for the manufacture compatibility with cement and the hydration test results showed that cork granules (both natural and expanded) are compatible with cement and can be added up to $30 \%$.

The aim of this study is to investigate the expansion process (mixing procedure) and parameters involved (time of the reaction and expansion volume) to produce foamed lightweight materials using different combinations of mud waste (MW), grounded glass (GG), metakaolin (MK) and expanded granulated cork (EGC) mixed with sodium silicate and sodium hydroxide, while using AL powder as a foaming agent. 

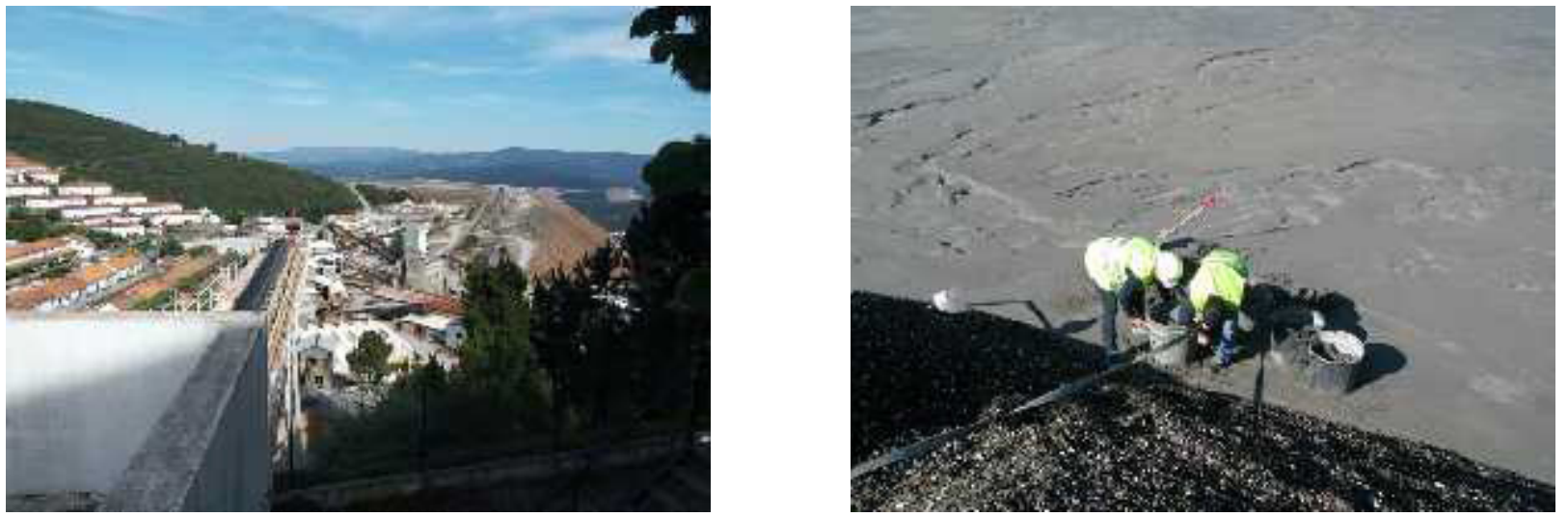

Fig 1. Panasqueira mine, Covilhã, Portugal: Left: panoramic view of mine plant. Right: collection of mud from waste deposits.

\section{Materials and methods}

\subsection{Materials}

The materials used in the study reported were mud waste (MW), grounded glass (GG), metakaolin (MK) and expanded granulated cork (EGC). The size of all powders was under $300 \mu \mathrm{m}$ and cork particles sizes range between 2 and $4 \mathrm{~mm}$.

The mud waste (MW) obtained from Panasqueira tungsten mine was used after the preparation and passing through a $300 \mu \mathrm{m}$ sieve as aluminosilicate rich precursor. Waste glass (GG) from glass bottles was also crushed and prepared at UBI's laboratory. Metakaolin (MK) provided by BASF with Specific Gravity of 2.50 ( $\mathrm{g} / \mathrm{cm} 3)$ and $\mathrm{pH}=6$ (28\% solids).

Aluminium (AL) powder used was provided by ACROS Organics with purity and molar mass of $99 \%$ and 26.98 Al respectively.

The expanded granulated cork (EGC) used was provided by (SOFALCA Sociedade Central de Produtos de Cortiça, Lda, Abrantes, Portugal). Figure 2. shows the cell structure of the expanded granulated cork.

Typical chemical compositions of the powders are shown in table 1. Composition was determined, in several samples of $\mathrm{MW}, \mathrm{GG}$ and $\mathrm{MK}$, by energy dispersive spectrometry (SEM/EDS) at UBI's optical center.

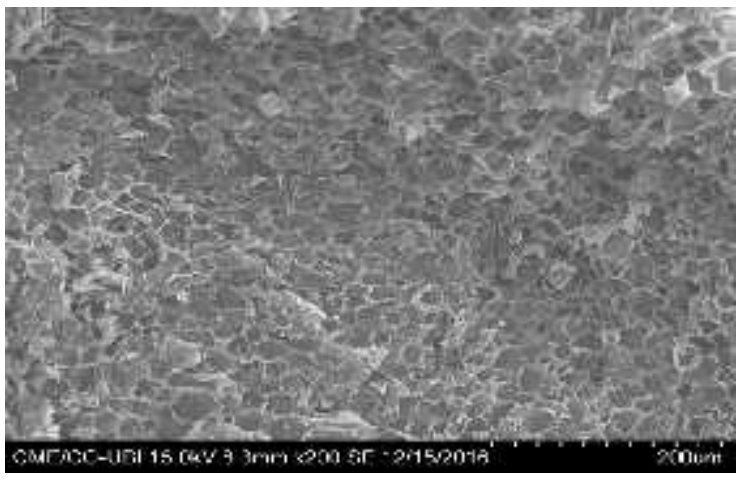

Fig. 2. SEM image of the expanded granulated cork (high magnification, UBI optic center).
A commercial sodium silicate $\left(\mathrm{Na}_{2} \mathrm{SiO}_{3}\right)$ (SS) solution with composition $\mathrm{SiO}_{2} / \mathrm{Na}_{2} \mathrm{O}=3.2$, and Sodium hydroxide $(\mathrm{NaOH})(\mathrm{SH})(98.6 \%$ purity) pellets dissolved in distilled water were mixed to constitute the alkali activator, which was prepared in the laboratory at the University of Beira Interior. The chemical composition of the activators was given by suppliers (Quimialmel Quimicos e Minerais, Lda. José Manuel Gomes dos Santos, Lda.) are shown in table 2.

Table 1. The chemical composition of MW, GG MK characterized by SEM.

\begin{tabular}{|c|c|c|c|}
\hline \multirow{2}{*}{$\begin{array}{c}\text { Chemical } \\
\text { components }\end{array}$} & \multicolumn{3}{|c|}{ Composition (\% w/w) } \\
\cline { 2 - 4 } & $\begin{array}{c}\text { Mud } \\
\text { waste }\end{array}$ & $\begin{array}{c}\text { Grounded } \\
\text { glass }\end{array}$ & Metakaolin \\
\hline $\mathrm{SiO} 2$ & 46.67 & 68.13 & 52.28 \\
\hline $\mathrm{Al} 2 \mathrm{O} 3$ & 19.01 & 2.80 & 42.99 \\
\hline $\mathrm{K} 2 \mathrm{O}$ & 4.90 & 0.86 & 0.94 \\
\hline $\mathrm{Na} 20$ & 0.85 & 12.52 & 0.32 \\
\hline $\mathrm{CaO}$ & 0.69 & 10.52 & - \\
\hline $\mathrm{SO} 3$ & 7.90 & 0.23 & - \\
\hline $\mathrm{Fe} 2 \mathrm{O} 3$ & 15.47 & 2.90 & 1.49 \\
\hline $\mathrm{MgO}$ & 4.83 & 2.04 & 0.47 \\
\hline
\end{tabular}

Table 2. The chemical composition of the activators.

\begin{tabular}{|c|c|c|}
\hline \multirow{2}{*}{$\begin{array}{c}\text { Oxide / } \\
\text { Materials }\end{array}$} & \multicolumn{2}{|c|}{ Chemical composition of activators (g) } \\
\cline { 2 - 3 } & $\begin{array}{c}\text { Sodium silicate } \\
\text { (SS) }\end{array}$ & $\begin{array}{c}\text { Sodium } \\
\text { hydroxide(SH) }\end{array}$ \\
\hline $\mathrm{Na} 2 \mathrm{O}$ & 19.37 & 13.02 \\
\hline $\mathrm{SiO} 2$ & 62.60 & 0.00 \\
\hline $\mathrm{A} 12 \mathrm{O} 3$ & 0.90 & 0.00 \\
\hline $\mathrm{H} 2 \mathrm{O}$ & 142.32 & 43.27 \\
\hline
\end{tabular}




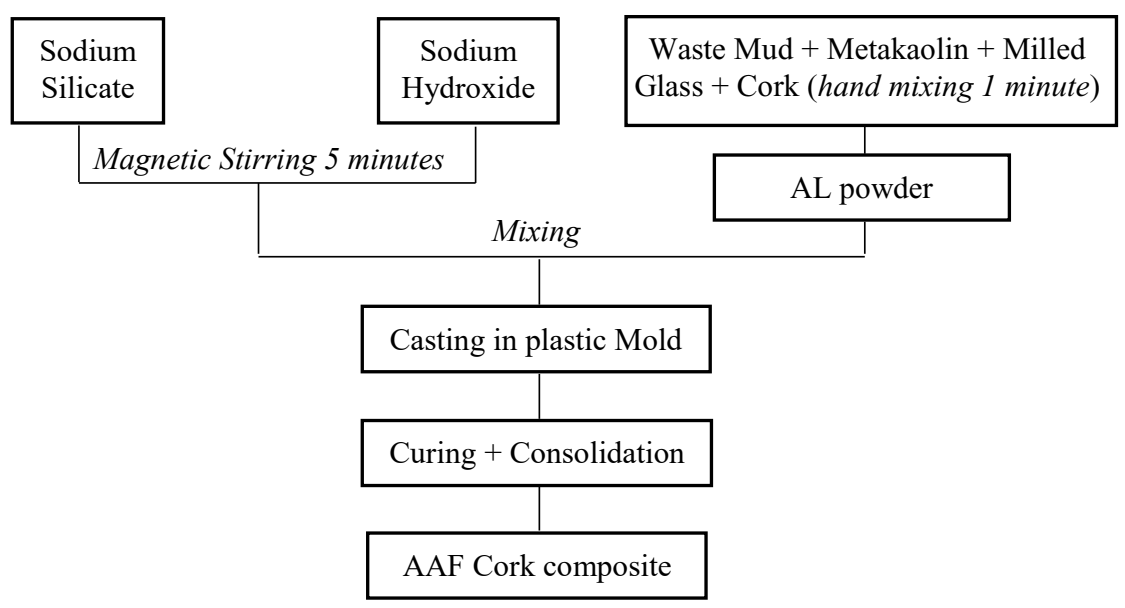

Fig. 3. Schematic process for the formation of lightweight alkali activated foamed material.

Table 3. detailed composition of the alkali activated composites.

\begin{tabular}{|c|c|c|c|c|c|c|c|c|c|}
\hline \multirow{2}{*}{ Samples } & \multicolumn{5}{|c|}{ Solid component (w.\%) } & \multicolumn{2}{|c|}{ Liquid component } & \multirow{2}{*}{$\begin{array}{c}\text { Expansion } \\
\text { volume (\%) }\end{array}$} & \multirow{2}{*}{$\begin{array}{l}\text { Reaction } \\
\text { time (Min) }\end{array}$} \\
\hline & MW & GG & MK & Cork & AL & & & & \\
\hline AL03 & 70 & 20 & 10 & - & 0.3 & SS & $\mathrm{SH}$ & 68.20 & $10 \mathrm{~min}$ \\
\hline AL05C25 & 70 & 20 & 10 & 25 & 0.5 & SS & $\mathrm{SH}$ & 17.10 & $3 \mathrm{~min}$ \\
\hline AL04C50 & 70 & 20 & 10 & 50 & 0.4 & SS & $\mathrm{SH}$ & 13.64 & $5 \mathrm{~min}$ \\
\hline AL05 & 70 & 20 & 10 & - & 0.5 & SS & SH & 68.20 & $5 \mathrm{~min}$ \\
\hline
\end{tabular}

\subsection{Composite synthes is}

The precursor was prepared by mixing dry powders of mud waste (MW), grounded glass (GG), metakaolin (MK) and cork as shown in figure 3. Different percentage of AL powder was added to the precursor which was then mixed with all dry components by hand for 1 minute. After the magnetic stirring at a rate of 400 r.p.m for about 5 minutes of $(10 \mathrm{M})$ sodium hydroxide (SH) with sodium silicate (SS), all components of the formulation were then mixed together for about 2 minutes at a medium speed. Several alkalis activated mixes were manufactured with the same ratio of precursor/activator, $\mathrm{P} ; \mathrm{A}=2.75$ and same activators ratio of SS; $\mathrm{SH}=3.1$ to study the influence of adding different percentage of $\mathrm{AL}$ powder on the expansion process as shown in table 3.

Various mixes were produced with different percentage content of AL powder; ranging between 0.3 wt. $\%$ to 0.5 wt.\%. The mixes were poured into $200 * 200 * 40 \mathrm{~mm}^{3}$ molds and were placed firstly in the oven at $60{ }^{\circ} \mathrm{C}$ for 24 hours for curing to speed up the alkali activation. After curing in the oven, the samples were demoulded and left to continue the curing in laboratory conditions for the following days until testing of the compressive strength after 28 days. The compressive strength test for the alkali activated foam was made with a very precise machine
(AUTOGRAPH AGS-X, $10 \mathrm{KN}$ SHIMADZU, at the mechanics of materials and mechanical technology laboratory, DECA UBI). All reported results are an average of 3 different measurements.

\section{Results and discussion}

\subsection{Mechanical properties}

As it was expected, the mechanical, bending and the compressive strength is strongly affected by the porosity and cork particles content in the alkali activated foamed cork composites. As shown in figure 4, The highest values for the compressive strength achieved was about 1.2 $\mathrm{MPa}$ for the mix M1 and M2, where the AL powder was added at $0.3 \mathrm{wt} . \%$. In addition, with the decrease of the density (the increase of cork particles content) compressive strength also decrease gradually. Flexural strength was determined using a three-point bending test on $40 \mathrm{~mm} \times 40 \mathrm{~mm} \times 160 \mathrm{~mm}$ samples and achieved $2.94 \mathrm{MPa}$ with 25 vol.\% of cork particles replacement. Figures 5 and 6 show the broken samples at bending and compressive strength test, and the cracking pattern of the samples respectively. 


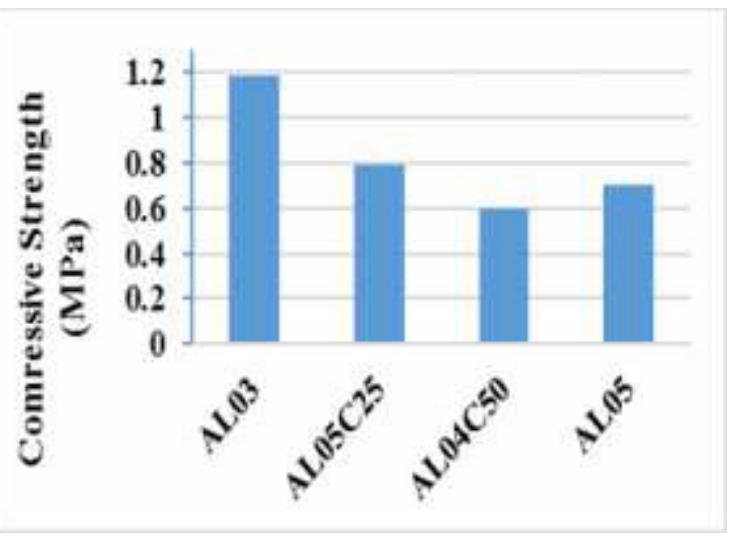

Fig. 4. Compressive strength diagram for the composites containing AL and cork.
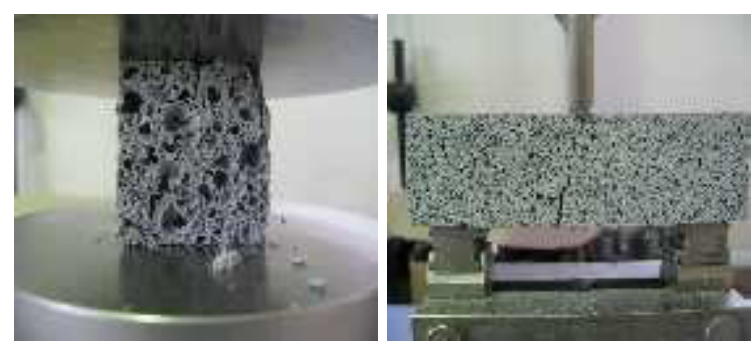

Fig. 5. Broken sample under bending and compressive strength test.
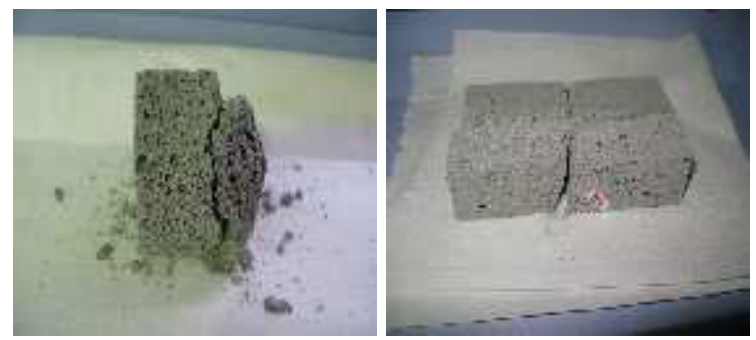

Fig. 6. The cracking pattern on samples.

\subsection{Dry density, porosity and expansion volume}

The density of the samples was measured by dividing the dry mass by the volume (i.e. so-called geometrical density). Cubic specimens $\left(40 * 40 * 40 \mathrm{~mm}^{3}\right)$ were used for dry density measurement's. In the case when cork particles were added the lowest foam composite density was achieved at about $542.02 \mathrm{Kg} / \mathrm{m}^{3}$ with 50 vol.\% of expanded granulated cork (M5 and M6). The dry density of the composites is reported in figure 7.

It can be observed that the increase of the AL powder enlarges the pore size of the samples. In addition, when adding large amount of foaming agent, the reaction between the AL metal powder and the alkaline activator $(\mathrm{NaOH})$ takes place very quickly, therefore the expansion is very fast and violent.

The expansion volume of the mixes was about $68.2 \%$ for all samples which didn't contain cork particles. Samples with 25 vol. $\%$ and 50 vol.\% of cork particles were achieved an expansion of $17.10 \%$ and 13.64 respectively. It can be clearly observed that the cork particles affect the expansion volume during the foaming process, it was also observed that the reaction time decrease with increased foaming agent content due to the faster reaction between AL powder and the catalyser $(\mathrm{NaOH})(10 \mathrm{~min}$ with $0.3 \mathrm{wt} \% \%$ and $3 \mathrm{~min}$ with $0.5 \mathrm{wt} . \%)$.

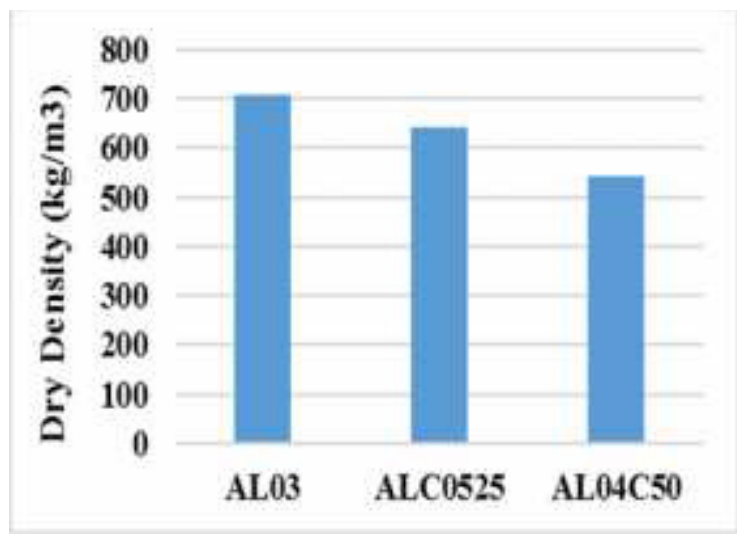

Fig. 7. The relation between cork content and density.

\subsection{Image analysis of the foams}

Images of the central foam section show a macrostructure with irregular spherical ultramacrospores derived from the foaming process. The degree of reactivity of the blowing agent and the homogeneity of the precursor affect the morphology of the pores (shape and diameter) and their distribution (regularity). The pore distribution of the alkali activated foam composites was presented in figure 8 .

The pore size is directly a result of the amount of foaming agent added, the analysis of particle size and its distribution of the foams composites was determined by "Image $J$ " software that could characterize individual particles (size, shape and surface) of the convex particles. The Feret diameter averaged over all directions $(\langle F\rangle)$ is equal to the ratio of the object perimeter $(\mathrm{P})$ and the number pi (constant of Archimedes), i.e., $\langle F\rangle$ $=\mathrm{P} / \pi$. There is no such relation between $\langle\mathrm{F}\rangle$ and $\mathrm{P}$ for a concave object. Figure 9 shows the histograms of the pore size of the foams composites.

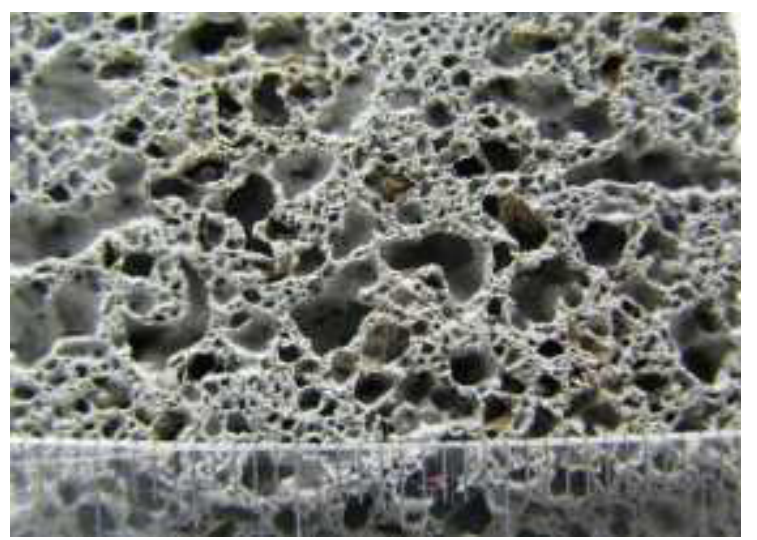

Fig. 8. Photographs of the central foam section of the sample. 

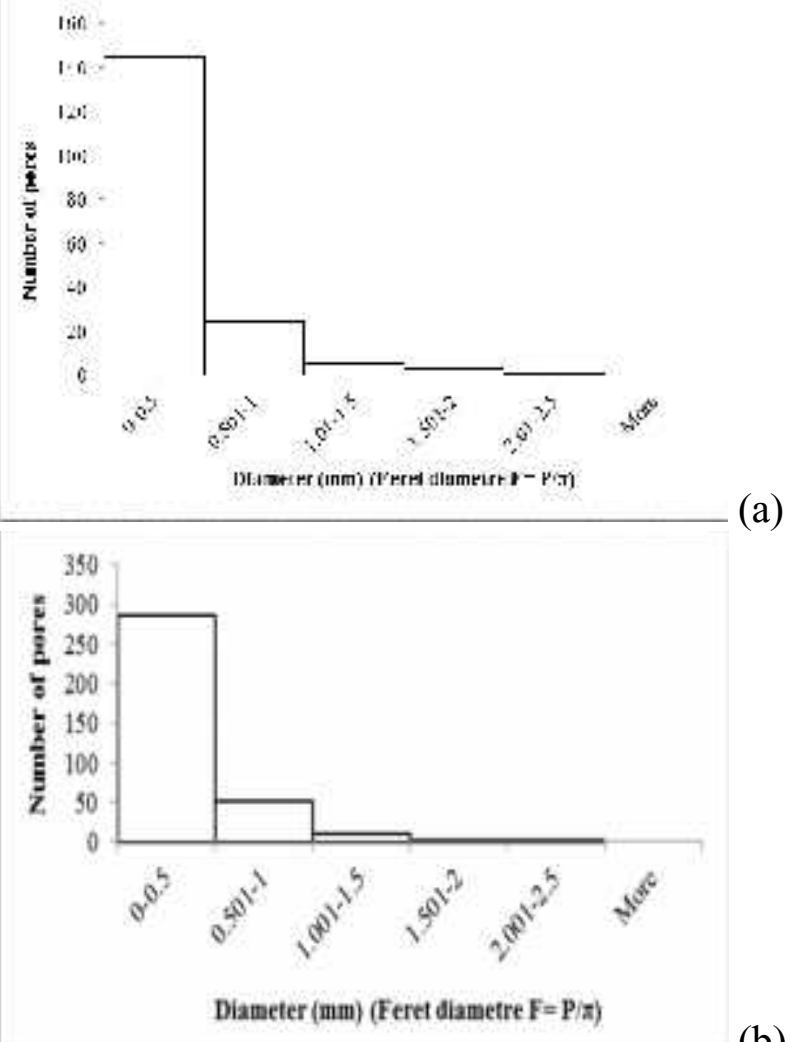

(b)

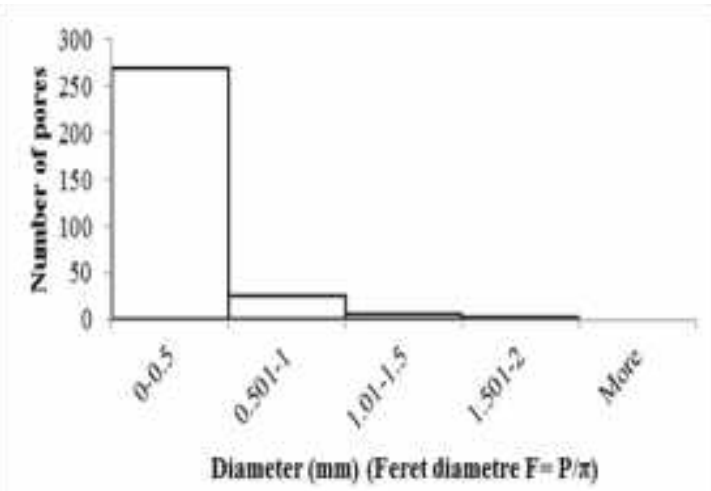

(c)

Fig. 9. Histograms for the pores size of the foam composites (a) $0 \%$ cork (b) $25 \%$ cork (c) $50 \%$ cork.

\section{Conclusion}

In this study, novel alkali activated foamed cork composites based on a tungsten mining mud waste were investigated. The research results confirm that the produced alkali activated foam cork composites have reasonable mechanical properties. The following findings were made:

- The compressive strength of the composites decreases as the cork particles content increase. However, without addition of cork, relatively high compressive strength is observed.

- In addition, during this study highly porous foams were produced by the use of the aluminium powder as blowing agent, and it is found that the density decrease as expanded granulated cork particles content increase due to the low density of cork particles.

- The expansion volume obtained by aluminium powder catalysed by the $\mathrm{NaOH}$ with the ratio $\mathrm{SS}$; $\mathrm{SH}=3.1$ is about $68.2 \%$ for all mixes without cork particles and about $17.10 \%$ and $13.64 \%$ with cork particles addition of 25 vol. $\%$ and 50 vol. $\%$ respectively.

\section{ACKNOWLEDGEMENT}

This research was partially supported by European Commission under Horizon 2020, Marie SklodowskaCuri Actions, Research and Innovation Staff Exchange (RISE), by REMINE - 'Reuse of Mining Waste into Innovative Geopolymeric-based Structural Panels, Precast, Ready Mixes and Insitu Applications", Project no $645696 \quad$ (https;//reminemsca.wordpress.com). Coordinator; Beira Interior University (PT) (participants; Brunel University (UK), Silesian University of Technology (PL), Bologna University (IT), Granada University (SP), Strathclyde University (UK), Alsitek Ltd (UK), Sofalca Lda (PT), Beira Serra (PT), Alfran (SP)), 01/01/2015 - 31/12/2018, project value $€ 567,000$ (EC contribution). This work was also partially financed by Portuguese national funds through FCT - Foundation for Science and Technology, IP, within the research unit C-MADE, Centre of Material and Building Technologies (CIVE-Central Covilhã-4082), University of Beira Interior, Portugal.

\section{References}

1. Torgal et al, "Utilization of mining wastes to produce geopolymeric binders 2009.pdf," 2009.

2. Castro-Gomes, "Valorizacao de residuos de minas em pavi," 2002.

3. F. Pacheco-Torgal, J. P. Castro-Gomes, and S. Jalali, "Investigations of tungsten mine waste geopolymeric binder: Strength and microstructure," Constr. Build. Mater., vol. 22, no. 11, pp. 2212-2219, 2008.

4. F. Pacheco-Torgal, J. P. Castro-Gomes, and S. Jalali, "Adhesion characterization of tungsten mine waste geopolymeric binder. Influence of OPC concrete substrate surface treatment," Constr. Build. Mater., vol. 22, no. 3, pp. 154161, 2008.

5. M. A. Longhi, E. D. Rodríguez, S. A. Bernal, J. L. Provis, and A. P. Kirchheim, "Valorisation of a kaolin mining waste for the production of geopolymers," J. Clean. Prod., vol. 115, pp. 265-272, 2016.

6. Z. Zhang, J. L. Provis, A. Reid, and H. Wang, "Geopolymer foam concrete: An emerging material for sustainable construction," Constr. Build. Mater., vol. 56, pp. 113-127, 2014.

7. Imed Beghoura. Castro- Gomes et al., "Feasibility of alkali-activated mining waste foamed materials incorporating expanded cork," Min. Sci., vol. 24, pp. 7-28, 2017. 
8. E. Ul Haq, S. Kunjalukkal Padmanabhan, and A. Licciulli, "Microwave synthesis of thermal insulating foams from coal derived bottom ash," Fuel Process. Technol., vol. 130, no. C, pp. 263267, 2015.

9. J. Feng, R. Zhang, L. Gong, Y. Li, W. Cao, and $\mathrm{X}$. Cheng, "Development of porous fly ashbased geopolymer with low thermal conductivity," Mater. Des., vol. 65, pp. 529-533, 2015.

10. Joseph Davidovits, "Geopolymer chemistry \& applications 3rd edition.” 2011.

11. V. Vaou and D. Panias, "Thermal insulating foamy geopolymers from perlite," Miner. Eng., vol. 23, no. 14, pp. 1146-1151, 2010.

12. M. Strozi Cilla, P. Colombo, and M. Raymundo Morelli, "Geopolymer foams by gelcasting," Ceram. Int., vol. 40, no. 4, pp. 5723-5730, 2014.

13. R. Arellano Aguilar, O. Burciaga Díaz, and J. I. Escalante García, "Lightweight concretes of activated metakaolin-fly ash binders, with blast furnace slag aggregates," Constr. Build. Mater., vol. 24, no. 7, pp. 1166-1175, 2010.

14. A. M. Matos, S. Nunes, and J. Sousa-Coutinho, "Cork waste in cement based materials," Mater. Des., vol. 85, pp. 230-239, 2015.

15. S. R. Karade, M. Irle, and K. Maher, "Influence of granule properties and concentration on corkcement compatibility," Holz als Roh - und Werkst., vol. 64, no. 4, pp. 281-286, 2006. 